\title{
Influence of acute renal failure on the mononuclear phagocytic system
}

\author{
V.R.A. Sousa ${ }^{1}$, A.A. Sousa ${ }^{1}$, \\ A. Petroianu1 ${ }^{1}$ C.J.R. Simal ${ }^{2}$ \\ and A.J.A. Barbosa ${ }^{3}$
}

\author{
Departamentos de ${ }^{1}$ Cirurgia, 2 Propedêutica, and ${ }^{3}$ Patologia, \\ Faculdade de Medicina, U niversidade Federal de Minas Gerais, \\ Belo Horizonte, MG, Brasil
}

\section{Correspondence \\ A. Petroianu \\ Av. Afonso Pena, 1626, Apto. 1901 \\ 30130-005 Belo Horizonte, MG \\ Brasil \\ Fax: + 55-31-274-7744}

Research supported by CNPq,

FAPEMIG and PRPq-UFMG.

Received October 18, 1999

Accepted June 5, 2001

\section{Abstract}

Several studies show the ability of macrophages to remove particles injected into the bloodstream. This function seems to be increased in the presence of acute renal failure. The objective of the present study was to assess the phagocytic function of the main organs (spleen, liver and lung) of the mononuclear phagocytic system in renal and postrenal failures. Fifteen rats (250-350 g) were divided into three groups $(\mathrm{N}=$ 5): group I - control; group II - ligature of both ureters, and group III bilateral nephrectomy. On the third postoperative day, all animals received an $i v$ injection of $1 \mathrm{ml} / \mathrm{kg}{ }^{99 \mathrm{~m} T c}$ sulfur colloid. Blood samples were collected for the assessment of plasma urea, creatinine, sodium, and potassium concentrations and arterial gasometry. Samples of liver, spleen, lung and blood clots were obtained and radioactivity was measured. Samples of liver, spleen, lung and kidney were prepared for routine histopathological analysis. Plasma urea, creatinine and potassium concentrations in groups II and III were higher than in group I $(\mathrm{P}<0.05)$. Plasma sodium concentrations in groups II and III were lower than in group I $(\mathrm{P}<0.05)$. Compensated metabolic acidosis was observed in the presence of postrenal failure. Group II animals showed a lower level of radioactivity in the spleen (0.98) and lung (2.63), and a higher level in the liver (105.51) than control. Group III animals showed a lower level of radioactivity in the spleen (11.94) and a higher level in the liver (61.80), lung (11.30) and blood clot (5.13) than control. In groups II and III liver steatosis and bronchopneumonia were observed. Renal and postrenal failures seem to interfere with blood clearance by the mononuclear phagocytic system.

\section{Introduction}

Infectious complications are still a major cause of morbidity and mortality in patients undergoing regular dialysis treatment. This increased morbidity and mortality in the presence of uremia seems to be due to dysfunction of polymorphonuclear leukocytes (1-4).

It has been established that the spleen can retain obsolescent red blood cells, harmful
Key words

- Renal failure

- Reticuloendothelial system

- Phagocytosis

- Macrophage

- Scintigraphy 
We have compared qualitative and quantitative methods for measuring spleen macrophage function by studying scintigraphic images corresponding to histological sections in different species which had received injections of radioactively labeled sulfur colloid and China ink (7).

Our results have shown that sulfur colloid without technetium or with ${ }^{99} \mathrm{Tc}$ or ${ }^{99 \mathrm{~m}} \mathrm{Tc}$, at doses as small as those employed in routine scintigraphy, is able to reduce significantly the splenic capture of tiny carbon particles (China ink). The data suggest that the impairment of splenic macrophage phagocytosis was caused only by the sulfur colloid (7).

Based on the literature and on our previous investigation, we conclude that the exhaustion of phagocytic cells and/or opsonins, or competition for blood components, may play a pivotal role in phagocytic impairment. Endocytosis of the sulfur colloid may be responsible for macrophage saturation. Another possibility is an inhibitory effect at the level of the macrophage membrane. A toxic effect of the colloid on macrophage functions has not been reported in the literature, and we did not find any alteration that might suggest this hypothesis (7).

The blood clearance of abnormal or foreign particles by phagocytic cells may be inhibited by previous administration of particles such as several colloids and heparin to the blood. Despite uncertainty concerning the mechanism of inhibition of blood clearance by prior administration of foreign particles, the process seems to operate at least partially through the blockade of the phagocytic mononuclear system by interfering with macrophage function $(8,10)$.

We believe it is worth to propose that the changes in internal environment provoked by uremia are able to modify the activity of different cells, including macrophages. If this is true, this phenomenon could influence the phagocytic function of this system. Following a line of research related to the mononuclear phagocytic system, we carried out the present investigation in order to determine the influence of renal and postrenal failures on the phagocytic function of the main organs (spleen, liver and lung) of this system.

\section{Material and Methods}

A pilot study was undertaken to assess survival time after surgical procedures using 10 rats divided into two groups $(\mathrm{N}=5)$ : group I, bilateral nephrectomy, and group II, ligature of both ureters. Survival time was $48 \mathrm{~h}$ for group I and $60 \mathrm{~h}$ for group II. The animals were highly uremic in both cases.

The study was carried out on 15 adult Wistar rats of both sexes weighing 250 to $350 \mathrm{~g}$, obtained from the Medical School of the Federal University of Minas Gerais. They were maintained in cages with up to five animals of the same sex, with free access to natural food and water. The animals were divided into three groups $(\mathrm{N}=5)$ : group $\mathrm{I}$ control (healthy animals - no procedures), group II - ligature of both ureters, and group III - bilateral nephrectomy.

The ligature of both ureters and nephrectomy were performed according to the following steps. Inhalatory ether anesthesia was offered before the beginning of the operation and when the rats started voluntary movements during the 30-min experiment time; no respiratory depression was observed. The abdominal cavity was entered through a midline incision.

\section{Group II}

Through a median laparotomy the retroperitoneal space was opened and both ureters were separated from surrounding tissue. Each ureter was cut in the middle of four ligatures (using 5-0 polyglycolic acid thread). The abdominal cavity of all rats was closed in two layers with 2-0 polyglycolic acid thread. 


\section{Group III}

The pedicles of both kidneys were dissected close to these organs in the retroperitoneum. The posterior parietal peritoneum and the tissue surrounding the kidneys were removed. The Gerota's fasciae of the kidneys were divided and separated from the adrenal glands. The renal pedicles were tied with 4-0 polyglycolic acid thread and both kidneys were removed. Hemostasis was carefully revised and the abdominal cavity was closed in two layers with 2-0 polyglycolic acid thread.

On the third postoperative day, all animals (groups I, II, and III) received an intravenous injection of ${ }^{99 m}$ Tc sulfur colloid (1 $\mathrm{ml} / \mathrm{kg}$ ) through the femoral vein, and were killed 30 min later by an inhalatory ether overdose. Blood samples $(4 \mathrm{ml})$ were collected from the vena cava for the assessment of plasma urea (enzymatic test), creatinine (colorimetric test), sodium and potassium (Ise selective electrode) concentrations. Samples of liver, spleen and lung $(2 \mathrm{~cm}$ each) were obtained and a 2-cm blood clot was also collected. Each of these samples was introduced into a small plastic cup and precisely weighed. Radioactivity measurements were verified by introducing the cups with the samples into a gamma-camera pinhole collimator. Radioactivity was assessed per gram of tissue. The total amount of radioactivity injected into each animal was considered to be 1 . Based on this value, the radioactivity determined in each organ was proportional to " 1 ".

An extra group of nine rats was studied in order to verify the presence of acidosis in animals with renal and postrenal failures. The animals were divided into three groups $(\mathrm{N}=$ 3): group I - control (healthy animals - no procedures), group II - ligature of both ureters, and group III - bilateral nephrectomy.

Blood samples $(4 \mathrm{ml})$ were collected by abdominal aorta puncture for arterial gasometry. This procedure was carried out under ether anesthesia, and the rats did not present any sign of respiratory failure during the 2min operative time.

Samples of liver, spleen, lung and kidney were removed from all rats, prepared for routine histopathological analysis, and stained with hematoxylin and eosin.

The mean values were analyzed statistically by ANOVA, with the level of significance set at $\mathrm{P}<0.05$.

\section{Results}

Table 1 shows that plasma urea, creatinine and potassium concentrations were higher in groups II and III than in group I $(\mathrm{P}<0.05)$. These levels were higher in group II than in group III. Plasma sodium concentrations were lower in groups II and III than in group $\mathrm{I}(\mathrm{P}<0.05)$. These levels were lower in group II than in group III.

Table 2 presents the mean values of arterial gasometry for the three groups. There was no significant difference between groups I and III. The presence of compensated meta-

Table 1. Plasma urea, creatinine, sodium and potassium concentrations of rats with renal and postrenal failures.

\begin{tabular}{lrrr}
\hline Parameters & \multicolumn{1}{c}{$\begin{array}{c}\text { Group I } \\
\text { (Control) }\end{array}$} & $\begin{array}{c}\text { Group II } \\
\text { (Ureter ligature) }\end{array}$ & \multicolumn{1}{c}{$\begin{array}{c}\text { Group III } \\
\text { (Nephrectomy) }\end{array}$} \\
\hline Urea $(\mathrm{mg} / \mathrm{dl})$ & $40.60 \pm 6.54$ & $686.20 \pm 62.69^{*}$ & $665.60 \pm 31.36^{*}$ \\
Creatinine $(\mathrm{mg} / \mathrm{dl})$ & $0.52 \pm 0.05$ & $10.02 \pm 1.96^{*}$ & $9.12 \pm 0.25^{*}$ \\
Sodium $(\mathrm{mmol} / \mathrm{l})$ & $141.00 \pm 1.86$ & $123.96 \pm 3.72^{*+}$ & $129.34 \pm 2.27^{*}$ \\
Potassium $(\mathrm{mmol} / \mathrm{l})$ & $3.03 \pm 0.37$ & $9.32 \pm 1.33^{*+}$ & $7.42 \pm 1.20^{*}$ \\
\hline
\end{tabular}

$* \mathrm{P}<0.05$ compared to control; $+\mathrm{P}<0.05$ compared to group III (ANOVA test).

Table 2. Arterial gasometry of rats with renal and postrenal failures.

\begin{tabular}{lccc}
\hline Parameters & \multicolumn{1}{c}{$\begin{array}{c}\text { Group I } \\
\text { (Control) }\end{array}$} & $\begin{array}{c}\text { Group II } \\
\text { (Ureter ligature) }\end{array}$ & \multicolumn{1}{c}{$\begin{array}{c}\text { Group III } \\
\text { (Nephrectomy) }\end{array}$} \\
\hline $\mathrm{pH}$ & $7.356 \pm 0.031$ & $7.318 \pm 0.05$ & $7.332 \pm 0.083$ \\
$\mathrm{pCO}_{2}(\mathrm{mmHg})$ & $41.567 \pm 10.169$ & $20.37 \pm 8.21^{*}$ & $37.600 \pm 11.692$ \\
$\mathrm{HCO}_{3}(\mathrm{mmol} / \mathrm{l})$ & $22.433 \pm 3.988$ & $10.43 \pm 4.86^{*}$ & $18.967 \pm 2.815$ \\
Base excess $(\mathrm{mmol} / \mathrm{l})$ & $-2.400 \pm 2.615$ & $-14.07 \pm 6.09 *$ & $-5.967 \pm 2.255$
\end{tabular}

$* \mathrm{P}<0.05$ compared to control (ANOVA test). 
bolic acidosis was observed in group II when compared with group I $(\mathrm{P}<0.05)$. There was no significant difference between groups II and III.

The proportional and real mean radioactivity values in each sample (liver, spleen, lung and blood clot) are presented in Table 3.

The animals of group II showed a lower level of radioactivity in the spleen $(\mathrm{P}=$ 0.000009 ) and lung than the control group. However, the animals of group II had a higher level of radioactivity in the liver $(\mathrm{P}=$ 0.000006) compared with the control group. The level of radioactivity in the blood clot was not different from the control group.

The animals of group III showed a lower level of radioactivity in the spleen $(\mathrm{P}<0.0006)$ than the control group and a higher level in the liver, lung and blood clot than the control group, although the difference was significant only for the blood clot $(\mathrm{P}<0.04)$.

Group II presented a lower level of radioactivity in the spleen, lung and blood clot, and higher levels in the liver compared to group III $(\mathrm{P}<0.03)$.

Histologically, group I presented moderate focal active pyelonephritis in one kidney sample. The other samples did not present any important alterations. Group II presented irregular, mild to moderate dilation of the renal tubules, tubular epithelium atrophy with the presence of hyaline casts inside the distal tubules, capillary compression and conse- quent anemia of the organ. This picture is compatible with mild to moderate early hydronephrosis (Figure 1).

Groups I and II did not present important morphological alterations as far as the spleen is concerned. Chronic and relatively intense congestion was observed in group III.

In group I, histology of the liver showed moderate to diffuse vacuolar or hydropic damage to the hepatocytes and small areas of necrosis with focal collapse of trabeculae. The liver of groups II and III presented diffuse steatosis. In group I, histology of the lung did not show any important alterations. In groups II and III, small focuses of discrete bronchopneumonia were observed (Figure 1).

\section{Discussion}

Renal failure is characterized by important hydroelectrolyte alterations and the accumulation of nitrogen compounds. Patients with this syndrome present frequent infections and are usually susceptible to a high rate of sepsis (5). In our study, the acidosis, the high level of urea, creatinine and potassium as well as the low level of sodium in plasma confirmed the presence of renal failure. The group submitted only to ureter ligature had more severe electrolytic disturbances probably due to the maintenance of the kidneys affected by urinary retention. This con-

Table 3. The proportional and real values of radioactivity (99mTc sulfur colloid - $110 \mathrm{mBq}$ ) in the mononuclear phagocytic system organs and blood of rats with renal and postrenal failures.

\begin{tabular}{|c|c|c|c|c|c|c|}
\hline \multirow[t]{2}{*}{ Samples } & \multicolumn{2}{|c|}{ Group I (Control) } & \multicolumn{2}{|c|}{ Group II (Ureter ligature) } & \multicolumn{2}{|c|}{ Group III (Nephrectomy) } \\
\hline & Proportional & Real $(m B q / g)$ & Proportional & Real (mBq/g) & Proportional & Real $(\mathrm{mBq} / \mathrm{g})$ \\
\hline Liver & $0.599 \pm 0.030$ & $65.82 \pm 3.29$ & $0.962 \pm 0.016 *$ & $105.51 \pm 1.76 *$ & $0.625 \pm 0.305^{+}$ & $68.75 \pm 33.55^{+}$ \\
\hline Spleen & $0.345 \pm 0.039$ & $37.92 \pm 4.29$ & $0.008 \pm 0.004 *$ & $0.98 \pm 0.44^{*}$ & $0.122 \pm 0.073^{*+}$ & $3.42 \pm 8.03^{*+}$ \\
\hline Lung & $0.050 \pm 0.028$ & $5.54 \pm 3.08$ & $0.023 \pm 0.015$ & $2.63 \pm 1.64$ & $0.083 \pm 0.019^{+}$ & $9.13 \pm 2.09^{+}$ \\
\hline Blood clot & $0.004 \pm 0.002$ & $0.44 \pm 0.22$ & $0.003 \pm 0.001$ & $0.33 \pm 0.11$ & $0.017 \pm 0.01^{*+}$ & $1.87 \pm 1.10^{*+}$ \\
\hline
\end{tabular}

Radioactivity was assessed per gram of tissue. The total amount of radioactivity for all samples from each animal was considered to be 1 . Based on this value, the radioactivities determined were proportional to " 1 ".

$* \mathrm{P}<0.05$ compared to control; $+\mathrm{P}<0.05$ compared to group II (ANOVA test). 
dition may have contributed to the higher electrolytic alteration in this group.

Previous studies on diabetic patients have suggested a possible interference of ketoacidosis with monocyte receptors, provoking functional disturbances in these cells. Lactic acid interferes with tumor necrosis factor, influencing the defense mechanisms (1113). In the present investigation we assessed the presence of acidosis as a factor able to complicate the acute renal failure and to interfere with the mononuclear phagocytic system. Since the metabolic acidosis of our animals was compensated, a possible interference of this disturbance was not taken into consideration.

The blood clot radioactivity indicates the rate of sulfur colloid in the circulation following its intravenous injection. An elevated radioactivity suggests the reduction of clearance by the reticuloendothelial system, which has been reported to be provoked at least in part by phagocytic cell inhibition or opsonin depletion (14).

In our study, both the renal and postrenal groups presented decreased spleen phagocytosis indicated by the reduction of ${ }^{99 \mathrm{~m} T c}$ sulfur colloid capture by the cells of the mononuclear phagocytic system. It may be proposed that this blockade does not depend on the presence of the kidney since the alterations occurred in both groups. Its exact mechanism remains to be investigated. Based on the literature, we may ascribe to the spleen an early filtering role. Following renal failure the macrophage functions reached their limit or were impaired and consequently foreign circulating bodies such as colloids

Figure 1. Histological sections from rats submitted to ligature of both ureters $(A)$ and ligature of both ureters plus nephrectomy ( $B$ and $C$ ). A, Renal medullar tissue presenting mild dilation of tubules and atrophy of the tubular epithelial cells. B, Hepatic parenchyma showing hepatocellular steatosis. C, Pulmonary parenchyma presenting small alveolar focuses of inflammatory cell infiltration. Hematoxylin and eosin stain. Magnification 200X.
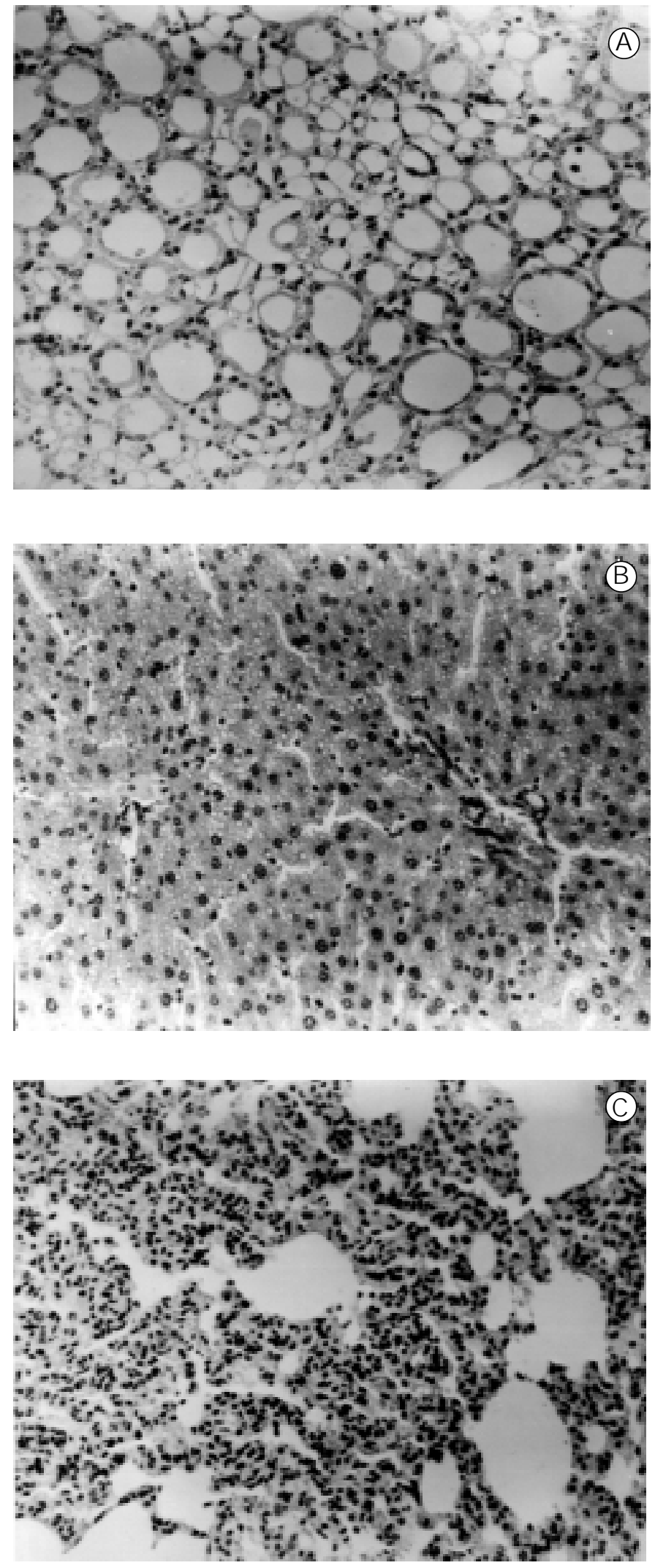
were less removed than they would be under normal conditions. However, we do not have enough data to propose colloid retention due to renal failure.

It is known that the liver, as the most important organ in the reticuloendothelial system, is able to increase its phagocytic role when necessary, enhancing colloid uptake. The efficacy of this process probably prevented the necessity of other organs to increase their phagocytic function (15-17).

We did not find any data in the literature to help us understand the differences in phagocytic function in the presence or absence of the kidneys. Further investigations are necessary to obtain more information about this phenomenon. Histology showed alterations usually found in the morphology of hydronephrosis due to urinary retention in the group submitted to ureter ligature. The histological picture of chronic congestion found in the spleen of nephrectomized rats was not specific and therefore did not provide enough data to explain its physiopathology.

It is known that patients with renal failure are more susceptible to pneumonia. The focal bronchopneumonia found in all groups suggests a possible role of the reticuloendothelial system in this susceptibility.

The results of the present study suggest that renal and postrenal failures interfere with blood clearance of the colloid by the mononuclear phagocytic system.

\section{Acknowledgments}

The authors gratefully thank Jair Pimenta Oliveira, M.D., Francisco Danilo Paula, B.S., and the Laboratory of Clinical Pathology of the University Hospital, Federal University of Minas Gerais. We thank Risa Andrade Sousa for revising the English text.

\section{References}

1. Haag WM \& Hörl WH (1996). Are granulocyte inhibitory proteins contributing to enhanced susceptibility to infections in uraemia? Nephrology, Dialysis, Transplantation, 11: 98-100.

2. Vanholder R \& Ringoir S (1992). Polymorphonuclear cell function and infection in dialysis. Kidney Intemational, 38 (Suppl): S91-S95.

3. Wierusz WB, Wysocki H, Michta G, Wykretowicz A, Czarnecki R \& Baczyk K (1984). Phagocytosis and neutrophil bactericidal capacity in patients with uremia. Folia Haematologica: Internationales Magazin für Klinische und Morphologische Blutforschung, 111: 589-594.

4. Vanholder R, Ringoir S, Dhondt A \& Hakim $R$ (1991). Phagocytosis in uremic hemodialysis patients. Kidney International, 39: 320-327.

5. Waymack J P, Rapien J, Garnett D, Tweddell J S \& Alexander W (1986). Effect of transfusion on immune function in a traumatized animal model. Archives of Surgery, 121: 50-55.

6. Kuhlmann MK, Shahmir E, Maasarani E, Akhtar S, Thevanayagam V, Vadgama J V \& Kopple JD (1994). New experimental model of acute renal failure and sepsis. J ournal of Parenteral and Enteral Nutri- tion, 18: 477-485.

7. Petroianu A, Simal CJR \& Barbosa AJA (1992). Impairment of phagocytosis by mammalian splenic macrophages by 99 mTc sulfur colloid. Medical Science Research, 20: 847-849.

8. Petroianu A \& Simal CJ R (1993). Shifts in the reticuloendothelial system uptake pattem induced by carbon colloid in the rat. Medical Science Research, 21: 311-312.

9. Petroianu A, Simal CJR \& Barbosa AJA (1993). Assessment of phagocytic function in remnants of subtotal splenectomy and in autologous spleen implantation. Medical Science Research, 21: 715-717.

10. Almeida LM, Melo MAB, Simal CJR \& Petroianu A (1996). Efeito da heparina sobre o sistema mononuclear fagocitário. Acta Cirúrgica Brasileira, 11: 15-18.

11. Rodriguez FG, Alcantarilla PR, Conde EV, Felix LR, Santana AM \& Madaria EZ (1985). Defect of monocytic recognition mediated by complement in hyperosmolar nonketotic coma and diabetic ketoacidosis. Revista Clinica Española, 176: 164168.

12. Rodriguez FG, Alcantarilla PR, Felix LR, Santana AM \& Madaria EZ (1985). Changes in the monocyte Fc receptor (IgG) in diabetic ketoacidosis and non-ke- totic hyperosmolar coma. Medicina Clinica, 84: 8-11.

13. J ensen J C, Buresh C \& Norton J A (1990). Lactic acidosis increases tumor necrosis factor secretion and transcription in vitro. J ournal of Surgical Research, 49: 350-353.

14. Normann SJ \& Beneditt EP (1965). Function of the reticuloendothelial system. J ournal of Experimental Medicine, 66: 709-719.

15. Pertosa G, Mastrolitti G, Späth PJ , Fracasso AR, Manno C \& Schena FP (1989). Effect of fibronectin on C3b and Fc receptor-mediated phagocytosis by peripheral blood monocytes in uremic patients. Nephrology, Dialysis, Transplantation, 4: 1520.

16. Oettinger CW, Bland LA, Oliver J C, Arduino MJ , McAlister SK \& Favero MS (1994). The effect of uremia on tumor necrosis factor-alpha release after an in vitro whole-blood endotoxin challenge. J oumal of the American Society of Nephrology, 4: 1890-1895.

17. Alexiewicz J M, Smogorzewski M, Akmal M, Klim M \& Massry SG (1996). Nifedipine reverses the abnormalities in $\left[\mathrm{Ca}^{2+}\right] \mathrm{i}$ and proliferation of $\mathrm{B}$ cells from dialysis patients. Kidney International, 50: 12491254. 